\title{
KARAKTER DAN LOKASI UNTUK PERANCANGAN ANIMASI PENDEK BERTEMA ADIKSI PADA SMARTPHONE
}

\author{
Stephanie Wenardy ${ }^{1)}$, Frans Santoso ${ }^{2)}$ \\ School of Design, Universitas Bina Nusantara \\ Jl. K. H. Syahdan No. 9, Kemanggisan, Palmerah, Jakarta 11480, Indonesia \\ stephaniewenardy@gmail.com
}

\begin{abstract}
Abstrak
Dalam animasi, karakter dan pengaturan lokasi atau lingkungan diperlukan sebagai alat untuk menyampaikan cerita. Desain visual yang baik dapat menarik perhatian penonton. Penelitian ini bertujuan untuk membantu pengembangan karakter dan latar belakang pengaturan dengan visual menarik yang mampu menyampaikan emosi dengan tepat dan menyampaikan pesan moral dari cerita tersebut. Topik yang diangkat adalah tentang kecanduan smartphone. Teknologi mampu membuat pengguna kecanduan. Dampak dari kecanduan ini tidak jarang membahayakan penggunanya. Desain animasi pendek ini menggambarkan bahaya yang mungkin dialami oleh pengguna karena kecanduan sehingga penting untuk menjaga keseimbangan dalam menggunakan teknologi, terutama smartphone. Penulis menggunakan metode kuantitatif dalam penelitian ini. Penelitian dilakukan dengan meninjau gambar referensi, studi literatur, melakukan survei, dan pengamatan. Hasil penelitian ini mengarah pada desain karakter, lokasi, cerita, dan aspek lain yang mendukung desain film animasi pendek.
\end{abstract}

Kata Kunci: Animasi, karakter, lokasi, kecanduan, smartphone

\begin{abstract}
In an animation, characters and location settings or environment are needed as a tool for delivering stories. A good visual design can attract the attention of the audience. This study aims to help character development and background settings with appealing visuals that are able to convey emotions appropriately and deliver the moral message of the story. The topic raised is about addiction to smartphones. Technology is able to make users addicted. The impact of this addiction is not uncommon to endanger its users. This short animation design illustrates the dangers that may be experienced by users due to addiction so it is important to maintain a balance in using technology, especially smartphones. The author uses quantitative methods in this study. The study was conducted by reviewing reference images, literature studies, conducting surveys, and observations. The results of this study lead to the design of characters, locations, stories, and other aspects that support the design of a short animated film.
\end{abstract}

Keywords: Animation, character, location, addiction, smartphone

\section{PENDAHULUAN}

Pemahaman mendasar mengenai desain karakter diperlukan agar dapat merepresentasikan karakter dengan baik dan dapat mendukung penyampaian cerita dengan tepat. Artist typically use shape, size, pose and proportion as the first design layer to express role, physicality and personality traits of a character (Islam et al., 2011). Visual yang menarik harus dilengkapi oleh kepribadian yang menarik dan mudah dipahami oleh penonton. A good character is one that is 
right for the story (Sullivan et al., 2013). Karakter yang baik akan mudah diingat dan dipercaya oleh penonton.

Ballon (2009) menyatakan bahwa "to truly create stories that will stick with the audience, a writer or designer must have the knowledge to design believable and pleasing characters". Penulis atau desainer perlu mempelajari mengenai desain karakter agar penonton tertarik dan percaya pada karakter yang diciptakan. Lokasi juga sama pentingnya dengan karakter karena keduanya saling mendukung dalam menyampaikan cerita. Oleh karena itu, pembelajaran lebih lanjut mengenai desain lokasi juga diperlukan karena lokasi merupakan dunia tempat karakter hidup dan berkembang.

Perkembangan teknologi seringkali memukau dan selalu menarik untuk diikuti. Interaksi antara manusia dengan teknologi pun sudah menjadi lazim, tetapi lambat laun hasil interaksi tersebut mulai berkembang ke arah yang mengkhawatirkan. Interaksi dengan teknologi semakin banyak. Bahkan tidak sedikit pengguna yang tidak bisa lepas dari teknologi dan mulai terkena dampak negatif akibat kecanduan. Khalaf dan Kesiraju (2017) dalam Flurry Analytics melaporkan bahwa rata-rata warga U.S. menggunakan perangkat seluler selama 5 jam per hari. Flurry memperlihatkan data bahwa durasi penggunaan perangkat seluler per hari oleh warga U.S. mengalami peningkatan setiap tahunnya. Data menunjukkan bahwa tahun 2016 mengalami peningkatan 20\% dibandingkan pada tahun 2015.

Tidak hanya di Amerika, efek kecanduan pada teknologi juga ditemukan di Indonesia. Seperti yang dilansir dalam artikel Kompas oleh Nistanto (2015), yang mengungkapkan hasil survei Google Indonesia yang dilakukan di Jakarta, Bodetabek, Bandung, Semarang, dan Surabaya pada periode Desember 2014 hingga Februari 2015. Berdasarkan survei tersebut, diketahui rata-rata warga Indonesia menghabiskan waktu selama 5,5 jam per hari menatap layar smartphone.

Penting disadari bahwa penggunaan yang berlebihan hingga menimbulkan efek candu bisa saja mencelakai pengguna. Dampak negatif dari kecanduan teknologi yang sering diangkat cenderung ke arah masalah sosial, misalnya kurangnya interaksi pengguna dengan individu lain. Akan tetapi, perancangan animasi pendek ini akan lebih memperlihatkan dampak yang bisa saja menghilangkan nyawa pengguna. Bukan hanya pengguna, orang dan lingkungan sekitarnya juga dapat terkena efek yang sama. Penulis mengharapkan pengguna teknologi dapat memanfaatkan kelebihan yang diberikan teknologi dengan baik dan mengurangi tindakan yang dapat menimbulkan malapetaka, baik bagi pengguna maupun sekitarnya.

Penulis mempelajari mengenai desain karakter dan lokasi yang menarik sehingga sesuai untuk digunakan sebagai salah satu alat penyampaian pesan cerita dalam animasi pendek. Penulis juga mengkaji hubungan individu dengan teknologi, khususnya smartphone, yang dinilai sudah menjadi adiksi bagi masyarakat luas. Penelitian ini dilakukan agar dapat menghasilkan perancangan karya animasi pendek yang dapat memberikan hiburan, tuntunan, sekaligus penyadaran kepada penonton sehingga terhindar dari bahaya akibat kecanduan pada smartphone.

\section{KAJIAN LITERATUR}

\section{Character design}

Shapes are what we fundamentally use to define what certain things are and what they possibly can be used for (Tillman, 2011). Dalam bukunya, Tillman menjelaskan bahwa umumnya bentuk menyampaikan makna tertentu. Makna tersebut didapat dari hasil pemikiran manusia yang cenderung mengasosiasikan bentuk dengan sifat-sifat tertentu.

Bentuk kotak memberi kesan stabilitas, keyakinan, kejujuran, teratur, keamanan, maskulin, dan kesesuaian. Sementara bentuk segitiga memberi kesan energi, ketegangan, konflik, aksi, agresi, dan licik. Bentuk bulat memunculkan kesan kelengkapan, keanggunan, ceria, menghibur, kesatuan, proteksi, dan kekanak-kanakan.

Bentuk tidak hanya digunakan untuk mendesain wajah atau kepala karakter, tetapi juga untuk bagian badan. Pixar dalam website-nya membagikan proses desain karakter dari salah satu animated feature mereka yaitu $U p$ (2009). Pixar menyatakan bahwa tokoh-tokoh dalam film $U p$ benar-benar mengaplikasikan bentuk. Mereka percaya bahwa isyarat visual dasar menyampaikan 
banyak hal tentang kepribadian, sehingga para pembuat film mematangkan karakter sampai ke esensi fisik mereka. Carl dibentuk seperti batu bata, terbebani dan tahan terhadap perubahan. Russell berbentuk seperti telur terbalik, tak berdosa, tak terselesaikan, dan optimis.

Sullivan et al. (2013) dalam bukunya menjelaskan bahwa desain karakter yang baik memiliki beberapa karakteristik sebagai berikut:

1. Be immediately recognizable and relatable

Poin dari karakteristik ini adalah untuk melibatkan penonton dan membangun empati, perhatian, atau setidaknya rasa ingin tahu tentang karakter sesegera mungkin.

2. Have a recognizable shape

Bentuk memiliki makna tersendiri. Contoh yang sering digunakan adalah bentuk lingkaran cenderung bersifat organik, siklis, dan innocent. Sementara kotak memberikan kesan buatan manusia dan padat. Sebagian besar karakter dibangun dari kombinasi bentuk dasar dan memiliki siluet geometrik agar mudah dikenali.

3. Reflect the personality of the character

Karakter perlu diekspresikan dengan kepribadian dan gaya mereka yang unik. Membuat kepribadian berarti menggabungkan dua hal, yaitu orisinalitas dan fungsi. Pemahaman profil karakter secara mendalam diperlukan untuk membuat karakter yang orisinil.

4. Include physical attributes that complement the content of the story

Cara lain untuk menemukan desain karakter yang unik adalah dengan melihat tujuan/gol dan konflik yang harus dihadapi karakter. Hal ini dapat sesederhana mendesain karakter yang ingin menjahit sebuah kancing tetapi memiliki jari yang sangat gemuk, atau karakter yang perlu menggaruk karena gatal tetapi memiliki lengan yang sangat pendek.

5. Be able to complete the actions that are required by the script

Salah satu tahap dalam mendesain karakter adalah mengujinya terhadap tindakan dan gerakan yang perlu dilakukan dalam cerita. Ekspresi emosi yang ekstrem dari karakter perlu diperhatikan. Wajah dan tangan adalah bagian tubuh yang paling ekspresif. Perlu dipikirkan mengenai tingkat kedetailan karakter dan bagaimana desain mempengaruhi waktu yang diperlukan untuk menganimasinya. Atribut yang tidak mendukung progres cerita perlu dipertimbangkan untuk tidak disertakan.

\section{Be interesting to watch}

\section{Environment Design}

Dalam membangun sebuah lokasi yang baik sebagai latar, Sullivan et al. (2013) mendeskripsikannya sebagai berikut:

\section{Sets the stage for the animation through props and space}

Beberapa karya paling canggih dalam animasi adalah desain lingkungan. Lingkungan telah inovatif dalam mendorong kemajuan visual dan teknologi sebagai elemen penceritaan yang penting. Lokasi bukan hanya latar belakang untuk sebuah karya. Ini bukan hanya ruang di mana karakter bertindak. Lokasi adalah dunia tempat karakter hidup.

\section{a. Props.}

Alat peraga adalah objek yang mengisi lingkungan yang digunakan karakter untuk mendorong cerita ke depan. Pemandangan tidak pernah sekedar bentang alam, kota hanya sebuah kota, bangunan hanya sebuah bangunan, atau sebuah ruangan hanya sebuah ruangan. Lokasi, dan benda-benda di dalamnya, spesifik untuk karakter dan ceritanya. Mereka memberikan banyak isyarat visual yang memberikan informasi seketika tentang karakter, latar belakang tokoh, dan situasi kepada penonton.

b. Space.

Ruang adalah area kosong dalam sebuah set yang harus cukup besar bagi karakter untuk melakukan hal yang perlu mereka lakukan. Apakah ini adalah interior yang sesak atau eksterior ekspansif yang luas, desain ruang harus mengarahkan penonton pada aksi penting dalam adegan. Oleh karena itu, perlu diberikan perhatian yang besar untuk menganalisis aksi dan menyusun alat peraga sedemikian rupa sehingga secara visual tidak 
mengganggu aksi dan agar mereka berada di tempat yang tepat ketika karakter perlu menggunakannya.

2. Determines the mood of the piece through texture, color, light, and design

Segera setelah film memudar dari hitam dan dimulai, kesan, emosi, perasaan, atau efek dramatis diciptakan oleh tekstur, warna, pencahayaan, dan elemen desain dari lokasi.

a. Tekstur. Segala sesuatu di sebuah lokasi memiliki tekstur - permukaan meja yang keras; kehalusan kelopak bunga; kekasaran jalan batu bata. Tekstur adalah kain, material, serat, biji-bijian, pola, fleksibilitas, atau kekakuan yang memberikan kualitas permukaan taktil ke benda-benda di dunia. Jumlah tekstur menentukan tingkat detail dan realitas dalam sebuah adegan. Semakin banyak tekstur dan detail yang dihadirkan, adegan tersebut menjadi semakin dekat dengan kenyataan bagi penonton.

b. Warna. Beberapa warna yang digunakan dalam suatu adegan didikte oleh apa yang disebut warna lokal. Ini adalah warna yang memiliki asosiasi alami. Rumput berwarna hijau; langit berwarna biru; lantai kayu berwarna cokelat, dan lain-lain. Warna lain digunakan untuk menciptakan emosi melalui asosiasi visceral, psikologis, atau budaya. Misalnya, hijau dikaitkan dengan alam, pertumbuhan, dan kelahiran. Tetapi hijau juga bisa berarti kurangnya pengalaman, keberuntungan, keserakahan, iri hati, kecemburuan, atau penyakit. Warna memiliki asosiasi emosional yang terbatas. Merah dan kuning memberi kesan hangat. Hijau dan biru memberi kesan dingin. Abu-abu memberikan kesan netral. Desain yang baik mengharuskan pemahaman rentang emosi yang dapat diciptakan oleh warna sehingga dapat diterapkan dengan serius dalam pekerjaan.

c. Pencahayaan. Unsur terpenting dalam menciptakan mood sebuah karya adalah cahaya. Banyak sinematografer menyebut cahaya sebagai cat untuk kanvas mereka, layar. Cahaya menunjukkan atau menyembunyikan detail penting, mendefinisikan bentuk, atau mengendalikan arah. Cahaya mengatur atmosfer, suasana, dan drama dari sebuah adegan melalui kualitas dan intensitas cahaya.

d. Elemen Desain. Garis, bentuk, skala, dan orientasi arah dari elemen-elemen dalam adegan mengkomunikasikan makna dan menciptakan gaya. Lingkungan yang terdiri dari bentuk-bentuk organik memiliki rasa yang sangat berbeda dibandingkan yang dibuat dengan bentuk geometris. Lengkungan, sudut siku, dan orientasi horizontal memberikan kesan menenangkan dan stabil. Diagonal, tepi runcing, vertikal berulang, dan perspektif tajam menciptakan energi dan ketegangan.

3. Supports the story

Segala sesuatu mengenai lokasi - alat peraga, ruang, tekstur, warna, pencahayaan, dan desain bergabung untuk mendukung cerita dan mengkomunikasikan periode waktu, genre, dan gaya dari sebuah karya. Lokasi harus mengkomunikasikan atmosfer, pencahayaan, dan desain dari karya tersebut.

4. A good location design creates intrigue, getting the audience quickly into the story

Untuk karya animasi pendek, visual dari lokasi harus membuat penonton masuk ke dalam cerita dengan cepat. Sama seperti desain karakter, desain lokasi membutuhkan visual yang menarik sehingga membuat penonton ingin tahu.

\section{Adiksi pada Smartphone}

Penggunaan smartphone yang berlebih sudah menjadi lazim. Excessive use of mobile phones has become an addiction in society (Fidan, 2016). Penggunaan berlebih ini bahkan menyebabkan adiksi/kecanduan yang dapat memberikan dampak negatif bagi pengguna.

Menurut Oxford Dictionaries, kata smartphone (/'sma:tfoun/) berarti a mobile phone that performs many of the functions of a computer, typically having a touchscreen interface, Internet access, and an operating system capable of running downloaded apps. Kata smartphone pertama kali digunakan pada tahun 1980an (yang mengacu pada telepon yang disempurnakan dengan teknologi komputer): dari kata smart dan phone.

Smartphone, atau telepon pintar, adalah jenis ponsel yang dibangun di atas sistem operasi seluler dengan kemampuan dan konektivitas komputasi yang lebih canggih daripada ponsel 
berfitur (Muduli, 2014). Smartphone memang mempunyai banyak kegunaan dan membantu pengguna dalam kehidupan sehari-hari. Akan tetapi, dampak positif yang diberikan rupanya mampu menimbulkan efek adiksi bagi pengguna.

Menurut Cambridge Dictionary, kata addiction (/ə'dikJ(ə)n/) berarti an inability to stop doing or using something, especially something harmful (English Dictionary) atau the need or strong desire to do or to have something, or a very strong liking for something (American English). Sementara menurut American Society of Addiction Medicine (2011), addiction is a primary, chronic disease of brain reward, motivation, memory and related circuitry.

Dalam sebuah artikel majalah Time yang ditulis oleh Heid (2016), dilampirkan pernyataan dari Dr. David Greenfield, assistant clinical professor of psychiatry di University of Connecticut dan pendiri dari Center for Internet and Technology Addiction. Beliau mengatakan bahwa hanya sebagian kecil orang yang memenuhi syarat sebagai kecanduan, tetapi banyak orang terlalu sering menggunakan smartphone mereka. Heid menyatakan batas antara terlalu sering menggunakan (overuse) dan kecanduan (addiction) abu-abu/samar. Tetapi Dr. Greenfield berkata bahwa seseorang pindah ke wilayah kecanduan saat tidak dapat berhenti menggunakan ponsel meskipun itu membahayakan hidupnya. "If you can't help being on it even when you know you shouldn't be, that loss of control is the hallmark of an addiction," kata Dr. Greenfield.

Heid (2016) juga menyertakan pendapat Dr. James Roberts, seorang professor marketing di Baylor University dan penulis Too Much of a Good Thing, buku tentang kecanduan smartphone. Beliau setuju dengan definisi Dr. Greenfield, dan memberikan beberapa tanda peringatan. Jika merasa cemas, mudah tersinggung, atau tidak nyaman ketika ponsel tidak dalam jangkauan, itu adalah peringatan. Dan menurut Dr. Roberts, keinginan yang terus meningkat untuk "dosis" smartphone sama dengan pelaku penyalahgunaan zat yang membangun toleransi terhadap obat-obatan atau alkohol.

\section{EXISTING STUDY}

\section{Studi Cerita Animasi Pendek Distracted (2018)}

Animasi pendek Distracted dibuat oleh Emile Jacques seorang mahasiswi Dawson College sebagai proyek final kelulusannya. Animasi tersebut mengisahkan tentang seorang ayah yang keasikan bermain handphone dan kecanduan hingga akhirnya tidak menyadari pertumbuhan anak perempuannya. Terlihat anak perempuannya berkali-kali berusaha menarik perhatiannya dengan mengajaknya bermain, memberikan kertas ulangannya ketika mendapat nilai bagus, dan memperlihatkan gambarnya, tetapi si ayah tidak pernah menghiraukan anaknya dan tetap terus bermain handphone. Pada akhirnya, terlihat sang ayah baru menyadari apa yang sudah ia lewatkan akibat kecanduannya pada handphone ketika anak perempuannya pergi meninggalkan dia karena sudah beranjak dewasa.

Animasi ini lebih berfokus pada dampak negatif perangkat teknologi terhadap relasi antar individu. Dalam kasus ini, relasi antara ayah dengan anaknya. Terlihat sang ayah yang tidak bisa lepas dari gadget-nya sehingga tidak mengacuhkan anaknya sendiri. Hingga pada akhirnya ia sendiri juga terkena dampak buruk yaitu kehilangan momen bersama anaknya. Sangat disayangkan ia baru menyadarinya ketika anaknya hendak pergi.

\section{Studi Cerita Animasi Pendek Glued (2012)}

Animasi pendek Glued dibuat oleh Alon Tako, Guy Elnathan, Daniel Lichter, dan Sivan Kotek yang merupakan sekelompok mahasiswa yang mempelajari animasi di Bezalel Academy of Arts and Design sebagai bagian dari program studi di tahun ke-3. Animasi pendek ini memperlihatkan seorang anak kecanduan bermain video game dengan media apapun. Sejak awal, anak tersebut bermain Play Station, komputer, Gameboy, PSP, dan masih banyak lagi.

Sang ibu yang melihat anak-anak lain bermain bola bersama di luar menjadi terdorong untuk menghentikan anaknya dari kecanduan video game dan menyuruh anaknya bermain di luar bersama anak-anak lain. Still frame pada gambar di atas, memperlihatkan salah satu scene anak yang sedang bermain. Gambar tersebut juga menunjukkan bagaimana anaknya asik bermain 
komputer tanpa menghiraukan kedatangan ibunya. Adegan-adegan selanjutnya memperlihatkan anaknya yang terus bermain video game sehingga sang ibu mulai gila dan menghancurkan semua mainan anaknya. Ia mengumpulkan semua mainan dan membawanya keluar rumah untuk dibakar.

Pada akhir film, sang anak yang tidak mempunyai pilihan lain akhirnya sudah mau bermain keluar dan ibunya sangat gembira, tetapi semuanya tidak semulus perkiraan ibunya. Anaknya bahkan tidak tau cara memainkan bola dan berusaha menggunakan remot kontrol untuk menggerakkan bola karena sudah terbiasa berhubungan dengan teknologi, yaitu bermain video game.

Animasi ini memperlihatkan efek negatif yang diterima sang anak, yaitu tidak memahami cara bermain bola karena sudah terlalu terbiasa bermain video game. Dampak negatif tersebut merupakan salah satu contoh dari sekian dampak yang mungkin muncul apabila individu kecanduan teknologi. Seperti dalam jurnal Muduli (2014), beliau membahas mengenai dampak negatif terhadap kesehatan mental pengguna perangkat teknologi secara berlebihan. Seseorang bisa saja kehilangan kemampuan berpikir secara logis sehingga sulit mencerna situasi atau hal akibat kecanduan teknologi.

\section{METODE PENELITIAN Metode Penelitian}

Penelitian merupakan research for design. Jenis penelitian yang akan dilakukan adalah kuantitatif. Menurut $K B B I$, kuantitatif berarti berdasarkan jumlah atau banyaknya. Menurut USC Libraries, penelitian kuantitatif menekankan pengukuran objektif dan analisis statistik, matematis, atau data numerik yang dikumpulkan melalui polls, kuesioner, dan survei, atau dengan memanipulasi data statistik yang sudah ada menggunakan teknik komputasi. Penelitian kuantitatif berfokus pada pengumpulan data numerik dan generalisasi di seluruh kelompok orang atau untuk menjelaskan fenomena tertentu. Teknik pengumpulan data berupa studi pustaka (buku, jurnal, internet), mengumpulkan referensi, survei, dan observasi.

\section{Metode Perancangan}

Terdapat 7 tahap metode desain yang dijelaskan oleh Gavin Ambrose dan Paul Harris (2015) dalam buku Design Thinking for Visual Communication yaitu:

1. Define

Pertama-tama, masalah desain dan target penonton harus ditentukan. Pemahaman jelas terhadap permasalahan akan menghasilkan solusi yang dapat dikembangkan. Tahap ini menentukan hal yang penting untuk kesuksesan proyek. Proses ini dapat dibantu dengan pertanyaan 5W 1H (Who, What, When, Where, Why, How).

\section{Research}

Tahap riset menganalisa informasi seperti akar permasalahan desain, wawancara, dan identifikasi potensi halangan yang muncul. Proses riset bisa menggunakan metode kuantitatif atau kualitatif. Teknik pengumpulan data primer mengikuti metode penelitian yang dipilih. Penelitian kuantitatif bisa mendapatkan data primer dengan melakukan survei. Sementara data primer dari penelitian kualitatif bisa didapat dengan wawancara. Selain itu, riset juga dapat dilakukan melalui data sekunder yaitu dari buku, jurnal, atau internet sehingga hasilnya berupa kajian literatur.

3. Ideate

Dalam tahap ini dilakukan identifikasi motivasi dan kebutuhan. Proses ini menghasilkan alternatif yang memiliki potensi untuk dilanjutkan. Ide bisa didapat melalui brainstorming maupun melihat referensi. 


\section{Prototype}

Setelah melalui tahap ideate, tahap ini membantu melihat hasil sementara dari ide yang sudah didapat, yang disajikan kepada sebagian orang terlebih dahulu sebelum ke target penonton. Dengan demikian, tahap ini sekaligus menguji produk dan pasar yang dituju.

5. Select

Pada tahap ini dilakukan seleksi untuk melihat ide mana yang berhasil dipraktikkan pada tahap sebelumnya yaitu prototype. Pemilihan dapat dilakukan berdasarkan masalah yang terjawab, tujuan yang terpenuhi dan respon dari pasar yang diuji.

6. Implement

Implementasi dilakukan dari hasil akhir pengembangan desain yang akan disajikan kepada klien. Pada tahap ini, solusi telah ditemukan dan menghasilkan hasil akhir desain.

7. Learn

Tahap ini diperlukan untuk pembelajaran bagi desainer dalam memperbaiki performa dan, dalam hal ini, desainer harus mencari klien dan target penonton untuk mendapat feedback dan melihat kesesuaian solusi dengan tujuan yang ingin dicapai. Hal ini dapat membantu jika ada rencana melakukan perbaikan atau peningkatan untuk selanjutnya.

\section{Ruang Lingkup Penelitian}

Ruang lingkup penelitian dibatasi hingga definisi adiksi pada smartphone dan beberapa analisis hubungan antardata hasil kuesioner yang dimasukkan ke dalam tabel dan grafik. Hasil penelitian dijadikan inspirasi dan landasan pengembangan cerita, karakter, dan lokasi dalam animasi pendek.

\section{HASIL DAN PEMBAHASAN}

\section{Analisa Hasil Kuesioner}

Penelitian kuantitatif dilakukan untuk mengetahui lebih lanjut mengenai topik kecanduan pada teknologi khususnya pada smartphone. Teknik pengumpulan data yang dilakukan adalah melalui survei. Penulis membuat kuesioner dengan Google Forms yang berisi rangkaian pertanyaan seputar hubungan individu dengan smartphone beserta dampak yang pernah dirasakan. Kuesioner dibagikan secara acak kepada masyarakat.

Tujuan utama kuesioner adalah untuk melihat ada tidaknya hubungan antara durasi penggunaan smartphone, yang bisa menjadi adiksi, dengan pernah tidaknya merasakan dampak negatif karena smartphone. Dalam hal ini, telah dijelaskan sebelumnya kepada responden bahwa dampak negatif yang dimaksud tidak hanya berarti kecelakaan besar yang mengancam nyawa responden, tetapi lebih kepada hal-hal negatif yang dialami atau dirasakan responden yang mampu memicu terjadinya bahaya atau kecelakaan lebih besar yang dapat berefek pada responden maupun sekitarnya. Misalnya hampir menabrak ketika berjalan/mengemudi, mata rusak, komunikasi tidak lancar, dimarahi guru, bertengkar dengan keluarga/teman, dan lain-lain.

Jumlah seluruh responden kuesioner ini adalah 230 orang. Dari 230 responden, terdapat 142 responden laki-laki dan 88 responden perempuan. Usia responden bervariasi dan dibagi menjadi 8 kelompok usia yang masing-masing kelompok memiliki jumlah responden serupa, yaitu berkisar antara 26-30 orang. Pengelompokan usia tersebut adalah 18-22 tahun, 23-27, 2832 , 33-37, 38-42, 43-47, 48-52, dan $\geq 53$ tahun. Persentase responden terbesar untuk durasi penggunaan smartphone adalah kategori lebih dari 6 jam per hari yaitu 37\% responden. Yang paling sedikit adalah 5\% untuk durasi penggunaan smartphone 1-2 jam per hari. 
Berdasarkan penelitian oleh Muduli (2014), penulis mengetahui bahwa durasi penggunaan smartphone berbanding lurus dengan keterikatan pada smartphone. Semakin lama durasi penggunaan smartphone, maka semakin kecanduan pula individu dengan smartphone mereka. Seseorang semakin terikat dengan smartphone mereka hingga dapat dikategorikan sebagai pecandu apabila menggunakan smartphone dalam durasi yang lama setiap hari dan menunjukkan efek atau gejala tertentu. Berdasarkan pada penelitian oleh Muduli tersebut, penulis menjadikan durasi penggunaan smartphone sebagai patokan tingkat kecanduan responden kepada smartphone mereka.

Mengetahui hubungan durasi penggunaan smartphone dengan pernah atau tidaknya responden mengalami dampak negatif karena smartphone merupakan tujuan utama dari survei yang dilakukan penulis. Durasi penggunaan smartphone akan dijadikan acuan tingkat kecanduan seseorang pada smartphone mereka.

Tabel 1 Hubungan antara durasi penggunaan smartphone dengan responden yang pernah mengalami dampak negatif karena smartphone

\begin{tabular}{lc}
$\begin{array}{l}\text { Durasi penggunaan smartphone } \\
\text { (per hari) }\end{array}$ & $\begin{array}{c}\text { Persentase responden pernah mengalami } \\
\text { dampak negatif karena smartphone (dalam \%) }\end{array}$ \\
\hline 1-2 jam & 9.09 \\
2-4 jam & 11.54 \\
4-6 jam & 20.73 \\
Lebih dari 6 jam & 22.35 \\
\hline
\end{tabular}

Berdasarkan tabel di atas, dapat dilihat secara jelas bahwa durasi penggunaan smartphone berbanding lurus dengan persentase responden pernah mengalami dampak negatif karena smartphone. Semakin lama seseorang menggunakan smartphone, semakin besar kemungkinan seseorang mengalami dampak negatif. Dapat dikatakan pula, semakin tinggi tingkat kecanduan seseorang pada smartphone, semakin besar kemungkinannya mengalami dampak negatif. Persentase terbesar responden mengalami dampak negatif pada kategori penggunaan smartphone lebih dari 6 jam per hari, yaitu 22.35\%. Meskipun angka persentase tidak signifikan, tetapi tetap memiliki resiko yang patut diperhatikan.

\section{Penulisan Judul}

Judul animasi pendek adalah 'Ana \& That Morning'. Dalam judul terdapat kata 'Ana' yang merupakan nama karakter utama dalam animasi pendek. Setelah kata 'Ana', terdapat kata '\& That Morning', dalam bahasa Indonesia berarti 'dan Pagi Itu', yang bermaksud memberi pesan kepada penonton bahwa kejadian utama dalam animasi pendek ini akan terjadi pada pagi hari. Dengan tambahan kata '\& That Morning', penulis ingin menimbulkan pertanyaan "apa yang akan terjadi pada pagi itu?" dalam benak penonton. Penulis memilih beberapa alternatif typeface untuk judul.

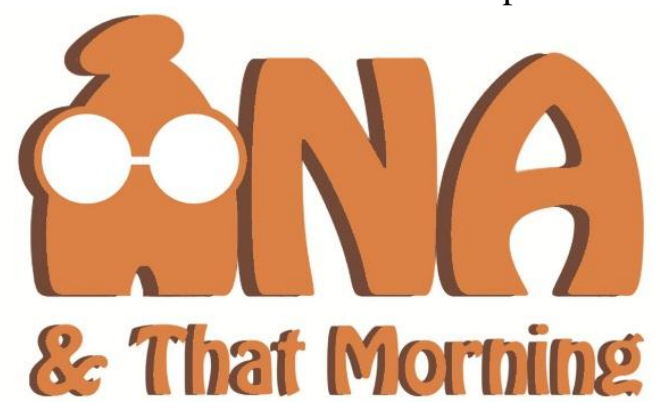

Gambar 1 Typeface judul Sumber: Dokumen Pribadi 


\section{Desain Karakter}

Karakter dalam film animasi pendek ini bernama Ana. Nama Ana dipilih karena merupakan nama yang universal, yang mudah ditemukan dalam berbagai negara. Misalnya di Indonesia maupun di negara asing ada pemilik nama Ana atau Anna, hanya berbeda sedikit dalam penulisan dan pelafalannya. Dalam animasi ini, Ana adalah seorang wanita dewasa muda usia 28 tahun yang menggunakan smartphone secara berlebihan hingga bisa dikategorikan ke tahap kecanduan.

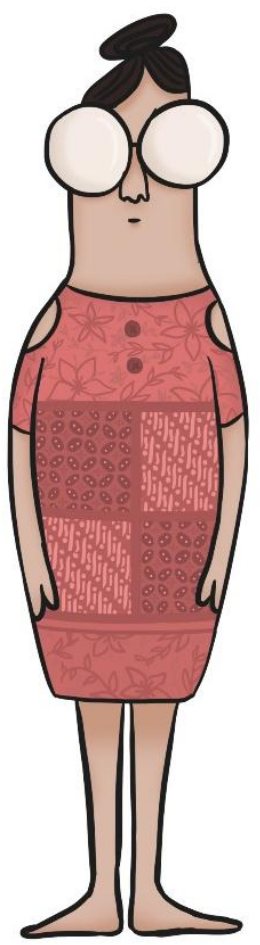

Gambar 2 Desain karakter Ana

Sumber: Dokumen Pribadi

Akibat kecanduan smartphone, tubuhnya menjadi sedikit gemuk karena malas bergerak. Karakter Ana memiliki bentuk dasar tubuh yang bulat agar terlihat sedikit gemuk dan tetap memberikan kesan lucu meskipun karakter memiliki sisi suram. Karakter Ana digambarkan memiliki mulut yang kecil karena jarang berkomunikasi. Ana menggunakan kacamata yang tebal karena matanya yang mulai rusak akibat terlalu sering melihat layar ponsel. Rambut Ana diikat sanggul agar terlihat santai berada di rumahnya. Ana mengenakan dress berhiaskan motif batik kawung dan batik parang. Pakaian Ana dan beberapa benda yang sering muncul bersama Ana (misalnya smartphone) didominasi warna merah muda. Hal ini agar karakter Ana terlihat lebih mencolok ketika berada dalam environment dapur yang didominasi warna jingga.

\section{Desain Lokasi}

Latar tempat dalam animasi pendek ini hanya satu yaitu dapur rumah Ana. Ana tinggal di rumah sederhana di Indonesia. Konsep interior dapur sederhana dengan sentuhan budaya Indonesia. Interior dapur menggunakan gaya open kitchen yaitu dapur dan ruang makan akan terintegrasi untuk pemanfaatan ruang yang sempit. 


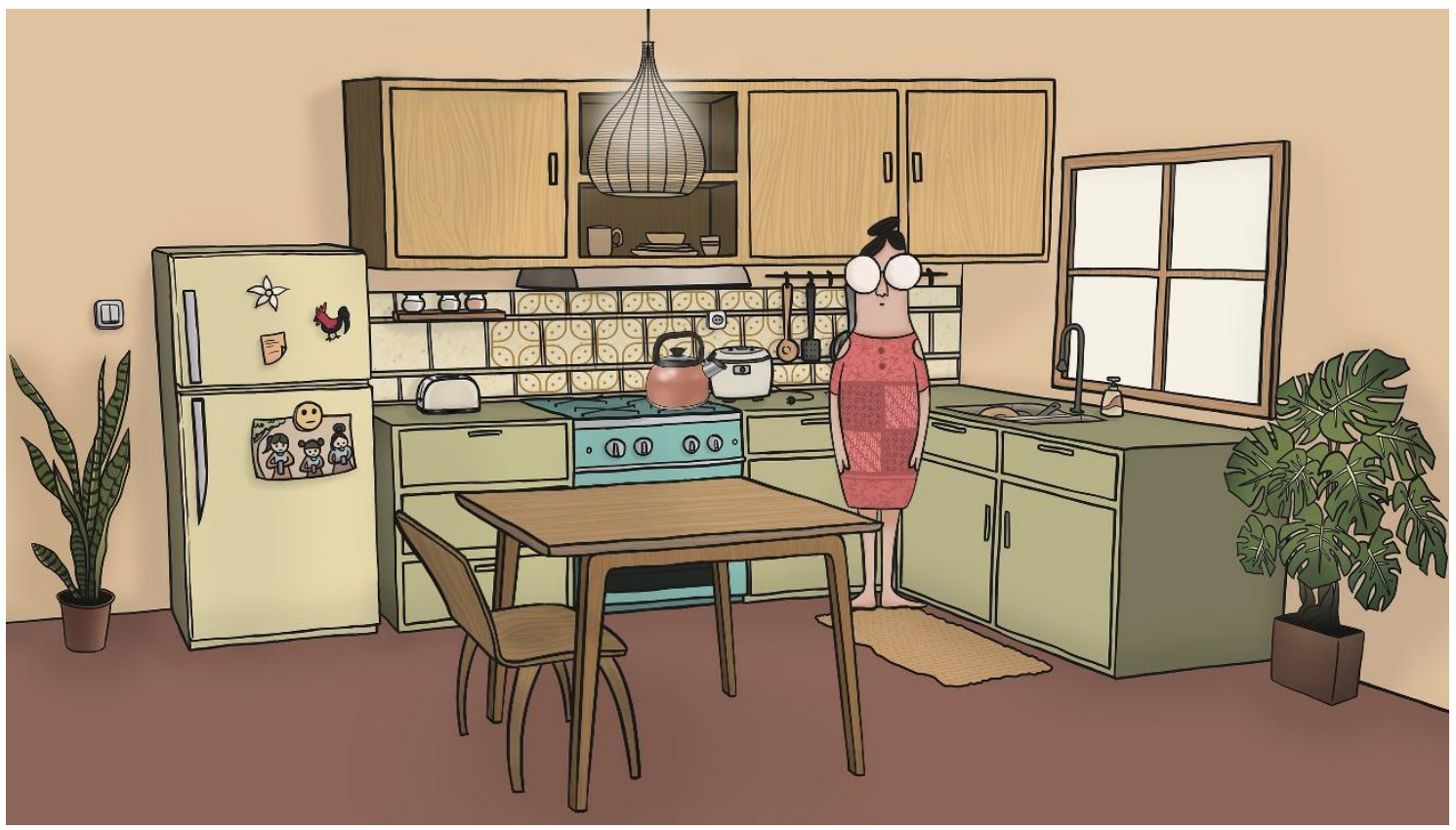

Gambar 3 Ana dan lokasi dapur

Sumber: Dokumen Pribadi

Beberapa perabotan rumah Ana menggunakan material lokal berupa kayu. Seperti furnitur meja makan beserta kursi yang memakai material kayu. Kemudian lemari penyimpanan peralatan makan dan kabinet dapur lainnya juga menggunakan material kayu. Dekorasi dan hiasan rumah Ana mengambil motif batik sebagai inspirasi. Motif batik yang banyak digunakan adalah motif batik kawung dan batik tumpal. Misalnya backsplash dapur menggunakan bata putih dengan dekorasi motif batik kawung. Beberapa peralatan makan seperti gelas memakai motif batik tumpal sebagai hiasan. Tanaman hias yang dipilih juga merupakan tanaman yang cukup sering dijumpai pada rumah-rumah di Indonesia, salah satunya yaitu tanaman lidah mertua.

Warna ruang dapur rumah Ana menggunakan color harmonies tipe complementary, yaitu didominasi warna merah-jingga dengan aksen warna biru-hijau. Penggunaan warna komplementer nyaman dipandang mata. Ruang dapur memberi kesan hangat (warm) karena memakai banyak warna dari sisi color wheel yang warm.

Meskipun memberikan kesan warm, menyesuaikan dengan alur cerita yang tidak cerah dan berakhir tidak terlalu bahagia, maka tingkat saturasi warna dapur direndahkan sehingga menampilkan keseluruhan warna dull. Aksen warna biru-hijau dapat dilihat digunakan pada kompor oven agar menjadi titik fokus dalam ruangan dapur sehingga ketika kejadian klimaks terjadi, mata penonton tertuju pada area di sekitar kompor.

\section{SIMPULAN}

Penelitian yang dilakukan penulis menjadi landasan perancangan animasi pendek. Hasil survei memperlihatkan bahwa individu yang kecanduan pada smartphone memiliki resiko mengalami dampak negatif yang lebih besar. Adiksi pada smartphone memberikan dampak negatif bagi pengguna yang tidak berhati-hati. Dibutuhkan pendekatan yang seimbang terhadap media dan teknologi. Seseorang tidak perlu meninggalkan smartphone, tetapi sebaiknya menghargai kualitas hidup. Pesan ini diangkat penulis menjadi cerita dalam animasi pendek dengan karakter utama seorang pecandu smartphone yang tidak menyadari bahaya yang mengancam ketika ia sibuk menggunakan smartphone. 


\section{DAFTAR PUSTAKA}

Addiction. (n.d.). Cambridge Dictionary. Diakses dari https://dictionary.cambridge.org /dictionary/english/addiction

Ambrose, G. \& Harris, P. (2015). Design thinking for visual communication. United Kingdom: Bloomsbury.

American Society of Addiction Medicine. (2011). Public policy statement: Short definition of addiction. Diakses dari https://www.asam.org/for-the-public/definition-of-addiction

Ballon, R. (2009). Breathing life into your characters: How to give your characters emotional \& psychological depth. Cincinnati: Writers Digest Books.

Fidan, H. (2016). Development and validation of the mobile addiction scale: the components model approach. Addicta: The Turkish Journal on Addictions, 3(3), 452-469. http://dx.doi.org/10.15805/addicta.2016.3.0118

Heid, M. (2016, Februari 24). You asked: Am I addicted to my phone? Time magazine. Diakses dari http://time.com/4234366/phone-smartphone-addiction/?xid=newsletter-brief

Islam, M. T., Nahiduzzaman, K. M., Why, Y. P., \& Ashraf, G. (2011). Informed character pose and proportion design. The Visual Computer, 27(4), 251-261. Diakses dari https://www.researchgate.net/publication/220067721_Informed_character_pose_and_pr oportion_design

Khalaf, S. \& Kesiraju, L. (2017, Maret 2). U.S. consumers time-spent on mobile crosses 5 hours a day. Diakses dari https://flurrymobile.tumblr.com/post/157921590345/us-consumerstime-spent-on-mobile-crosses-5

Kamus Besar Bahasa Indonesia. (n.d.). Diakses dari https://kbbi.web.id/kualitatif

Kamus Besar Bahasa Indonesia. (n.d.). Diakses dari https://kbbi.web.id/kuantitatif

Muduli, J. R. (2014). Addiction to technological gadgets and its impact on health and lifestyle: A study on college students (Master's thesis). Diakses dari http://ethesis.nitrkl.ac.in/5544/

Nistanto, R. K. (2015, September 4). Kebiasaan orang Indonesia, pelototi "smartphone" 5,5 jam sehari. Diakses dari https://tekno.kompas.com/read/2015/09/04/11301837/Kebiasaan. Orang.Indonesia.Pelototi.Smartphone.5.5.Jam.Sehari.

Pixar. (n.d.). Up. Dakses dari https://www.pixar.com/feature-films/up\#up-main [Oktober 19, 2018]

Oxford Dictionaries. (n.d.). Diakses dari https://en.oxforddictionaries.com/definition/smartphone

Sullivan, K., Alexander, K., Mintz, A., \& Besen, E. (2013). Ideas for the animated short: Finding and building stories. United Kingdom: Focal Press.

Tillman, B. (2011). Creative character design. United Kingdom: Focal Press.

USC Libraries. (2018, Oktober 5). Organizing your social sciences research paper: Qualitative methods. Diakses dari http://libguides.usc.edu/writingguide/qualitative 
USC Libraries. (2018, Oktober 5). Organizing your social sciences research paper: Quantitative methods. Diakses dari http://libguides.usc.edu/writingguide/quantitative 